\title{
Assessment of ozone effects on five varieties of tobacco via fumigation method
}

\author{
*M. Azadi \\ Department of Environmental Science, University of Queensland, Brisbane, Australia
}

\begin{abstract}
To assess the susceptibility of five varieties of tobacco to ozone, nine rounds of fumigation experiments were performed. These tobacco varieties were exposed to a range of ozone concentrations in a single-pass chamber fumigation system for short periods. A dose of $7.5 \mathrm{pphm}$ did not produce visible injury in any tobacco variety. Tobacco cultivars; Bel-B, Weather Fleck and ZZ100 exhibited no visible injury up to 26 pphm. However, doses in excess of 16 pphm caused visible injury in cultivars Bel-W3 and Dynes. Awareness of the susceptibility levels of these cultivars to ozone assist biological monitoring process in field experiments. Biomonitoring is considered to be a valuable method for ozone assessment for situations where air pollution monitoring by instruments in remote locations is too expensive.
\end{abstract}

Key words: Biological monitoring, fumigation, open-chamber system, ozone

*Email: mazadi23@yahoo.com

\section{Introduction}

The effect of a pollutant on a plant is greatly influenced by environmental regimes before, during, and after exposure to the pollutant as well as the nature of the exposure episode. Soil moisture and nutrient availabilities, photosynthetic radiant flux, temperature and relative humidity are very important in determining the rate of plant growth. They will also affect stomatal aperture, which determines the amount of gaseous air pollutant absorbed by a leaf and consequently the extent of effects and plant growth and the appearance of visible injury and also amount of injury (Mooi, 1986). Several different fumigation systems have been used to study the effects of air pollution on plants, for example fumigation glasshouses, open-top chambers or field fumigation systems and sometimes closed chambers maintained under defined conditions. Although these systems are useful, it is very difficult to reproduce experiments because of variations in environmental conditions. Experimental studies of air pollutant interactions with plants have been carried out for 30 years, and some earlier work is described by Mooi and Jolink 1989. In this study, responses of plants to ozone fumigation were assessed in terms of the relative degrees of injury of different varieties of tobacco (Nicotiana tabacum). Growth was not assessed. Controlled treatments using unfiltered ambient air are acceptable:

Ozone-induced injury does not occur in this treatment or the extent of injury that does occur can be assessed quantitatively and can be diagnosed as characteristisc for ozone. This fact is very important, as relative susceptibility depends on ozone exposure level, and 3-4 different ozone levels should be used. Other air pollutants such as $\mathrm{SO}_{2}$ and $\mathrm{NO}_{2}$ may interfere with the effects of ozone producing either synergism or antagonism. Thus, it is preferable to use charcoal filtered air than unfiltered air in the controlled treatments. In the United States, very elaborate fumigation methods have been used (Mooi and Jolink, 1989; Tingy, et al., 1972) with computerized environmental control and pollutant delivery.

Because of this complexity, the systems are expensive and therefore difficult to replicate. Simple method of fumigation was used in the present study, but it was sufficient for the purpose of this study to verify the indication of ozone injury to field studies (Lee, 1991 and Sun, 1994). 
Table 1: Concentration of ozone (pphm), temperature $\left({ }^{\circ} \mathrm{C}\right)$, humidity (wet and dry bulbs and average (humidity), and PAR $\left(10 \mu \mathrm{mol} / \mathrm{m}^{2} \mathrm{~s}\right)$ during nine rounds of fumigation

\begin{tabular}{|ccccccc|}
\hline $\begin{array}{c}\text { Number of } \\
\text { exposure }\end{array}$ & $\begin{array}{c}\text { Date of } \\
\text { exposure }\end{array}$ & $\begin{array}{c}\text { O3 Con. } \\
\text { pphm }\end{array}$ & $\begin{array}{c}\text { Temp. } \\
\left({ }^{\circ} \mathrm{C}\right)\end{array}$ & $\begin{array}{c}\text { Humidity } \\
\text { Av.w/Av. }\end{array}$ & $\begin{array}{c}\text { Humidity } \\
\text { Av. }\end{array}$ & $\begin{array}{c}\text { PAR } \\
\left(10 \mu \mathrm{mol}^{2} \mathrm{~m}^{2} \mathrm{~s}\right)\end{array}$ \\
\hline 1 & 24.4 .98 & 7.5 & 30 & $11.4 / 19.6$ & $35 \%$ & 1140 \\
\hline 2 & 27.4 .98 & 7.5 & 35 & $8.8 / 20.1$ & $16 \%$ & 1332 \\
\hline 3 & 29.4 .98 & 7.5 & 27 & $13.2 / 20.4$ & $43 \%$ & 430 \\
\hline 4 & 30.4 .98 & 16 & 29 & $13.0 / 21.8$ & $34.8 \%$ & 848 \\
\hline 5 & 5.5 .98 & 16 & 20 & $13.6 / 17.6$ & $64 \%$ & 160 \\
\hline 6 & 6.5 .98 & 16 & 20 & $10.9 / 19.87$ & $30.3 \%$ & - \\
\hline 7 & 1.5 .98 & 26 & 24 & $12.6 / 18.9$ & $47.5 \%$ & 244 \\
\hline 8 & 23.4 .98 & 26 & 29 & $16.2 / 21.5$ & $58 \%$ & 1120 \\
\hline 9 & 22.4 .98 & 26 & 29 & $15.5 / 24.1$ & $39.5 \%$ & 1150 \\
\hline
\end{tabular}

\section{Materials and Methods}

Plant species and varieties which were used for ozone test are as follows;

-Nicotiana tabacum cv.ZZ100

-Nicotiana tabacum cv. Dynes

(Susceptibility to be tested during the experiments process)

-Nicotiana tabacum cv. Weather Fleck

(Susceptibility to be tested during the experiments process)

-Nicotiana tabacum cv. Bel-W3

(Supersensitive variety)

-Nicotiana tabacum cv. Bel-B

(Tolerant variety)

Plants were grown from seed in a standard soil mix under glasshouse conditions. After about four weeks the seedlings were transplanted into cylinderical pots of about 750 $\mathrm{ml}$ capacity containing fresh soil mix. Three replicate plants of each variety (according to the experiments) were placed in the fumigation cabinet when about six to nine weeks old (four-seven leaf stage) and replaced by fresh (six to nine weeks old) plants for each round of fumigation. Meanwhile, although plants were grown in the glasshouse environment, but they were fully checked, and only plants with healthy leaves were exposed to ozone in the open-chamber fumigation system. Nine rounds of fumigation were performed in two months in 1998 (Table 1). The location of experiments was at the University of Queensland, Australia.

\section{Open chamber fumigation method}

The method used to fumigate plants in these experiments was in effect an open chamber, although the structure had been built as a closed, naturally illuminated and controlled environmental chamber.
-The fumigation cabinet had total dimensions of $157 \mathrm{~cm}$ long $\times 195 \mathrm{~cm}$ tall $\times 105 \mathrm{~cm}$ wide, with a $57 \mathrm{~cm}$ space between the plant platform and the base of cabinet (Figure 1). The roof and side walls were constructed from glass sheeting or sliding window sets, except at one end, where the air handling equipment was fitted to an aluminium sheet wall. A $30 \mathrm{~cm}$ axial fan drew air from beneath the plant platform and recirculated it to the top of the chamber, two to three times per minute. Fresh air was admitted to the system by having one or two of the sliding glass doors partially opened, the extent depending on local wind conditions. All the recirculating air was passed through a charcoal filter (Posthumus, 1977) $25 \mathrm{~mm}$ thick placed immediately upstream from the main filter (Posthumus, 1977; Tonneijck and Leone, 1993 and Tonneijck, 1994). Because charcoal filter air was used, and sufficient ozone was added to maintain stable concentrations within the chamber, the results can be interpreted, statistically. Meanwhile, as the ozone concentration was relatively stable during the actual fumigation periods, designation of graphs for them was not done. It does not seem to assist the fumigation results interpretation very much.

An ozone monitor/analyzer Model 8810 (Monitor Labs INC.) kindly provided by the Queensland Environmental Protection Agency was used to sample ozone concentrations immediately above the tops of plants in the chamber. Air was drawn continuously through about $7 \mathrm{~m}$. of $3 \mathrm{~mm}$ internal diameter teflon tubing. An ozone generator was constructed according to the design provided by Murdoch University of Australia. This generator was able to produce $100 \mathrm{pphm}$ of ozone in a 4.2 cubic meter cabinet in four minutes. Plant 


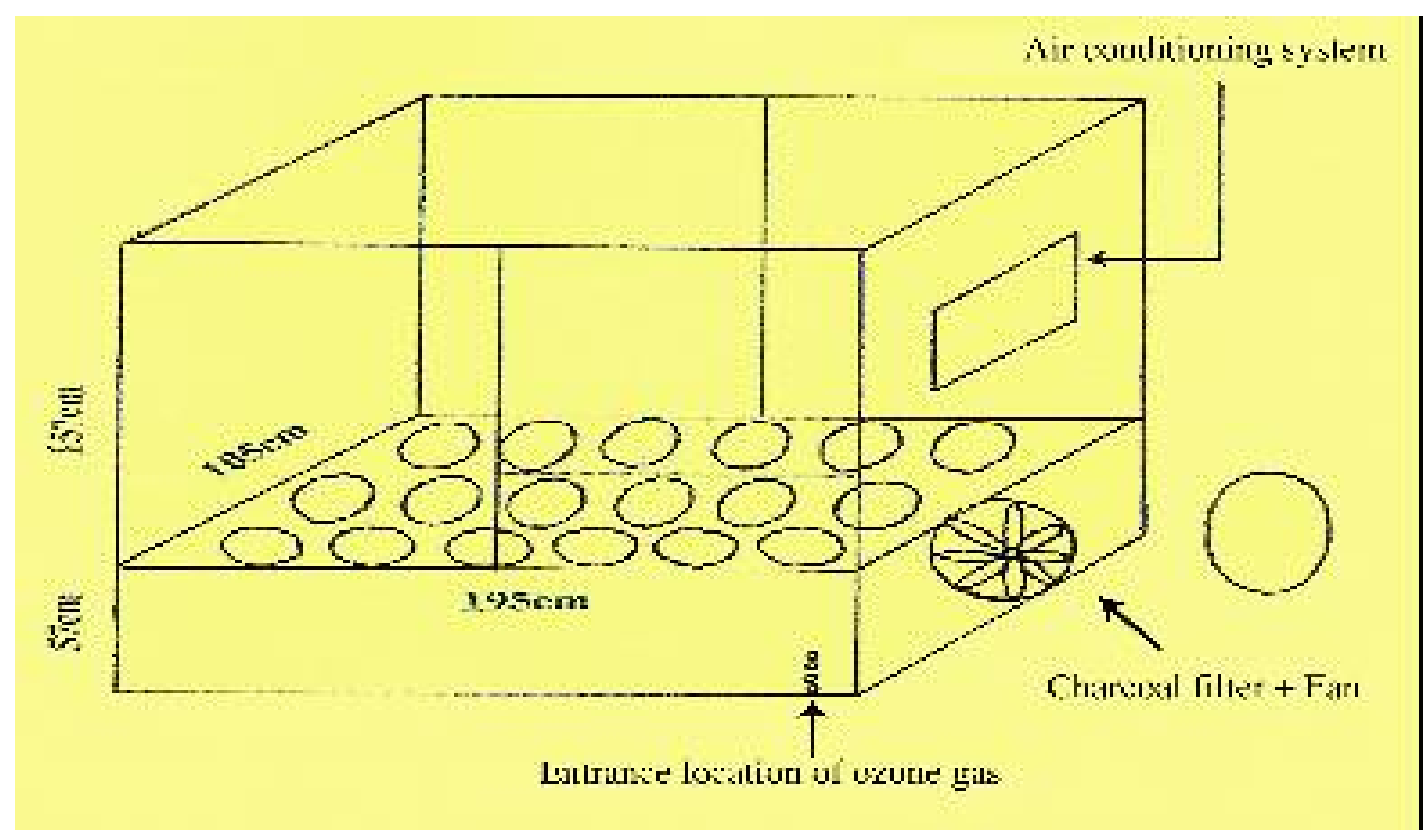

Figure 1: Design details of ozone chamber system used for ozone fumigation experiment

material and fumigation schedules; As only one cabinet was available for the experiments, replication was required at the treatment level not on the pot level.

For this purpose, 15 pots of five varieties of test plants (Nicotiana tabacum cv. Bel-W3; 3 pots, Bel-B; 3 pots, Weather Fleck; 3 pots, Dynes; 3 pots and ZZ100; 3 pots were fumigated in nine rounds of fumigation at different ozone concentrations. The problems with fumigations separated in time are;

- The ozone sensitivity of plants may change over the year. Thus, the results of experiments performed in different periods of the year may not be comparable.

- If ozone is added to unfiltered ambient air, then it is easy to understand that exposure profiles (concentration, etc.) of ambient ozone will vary in different times of the year.

Pots were covered with plastic bags. Before fumigation, plants were watered for keeping stomates open. Both doors of cabinet were open, plastic sheets with the size of $60 \times$ $86 \mathrm{~cm}$ covered the open area (to avoid the direct wind). Cooler was on and fan plus charcoal filter (2-3 air exchange per minute) were used in the experiments (Figure 1).

The exposure period was from 9 am to 4 pm. Nine fumigations were conducted. During all rounds of fumigation, 15 pots of 5 varieties of tobacco (Bel-W3, Bel-B, Dynes, ZZ100, Weather Fleck) were fumigated. After each round of fumigation the visible injuries were assessed as the percentage of leaf injured, and those were determined by visual estimate to increase the speed of assessment. This means that one leaf injury was measured very accurately and the other leaves were compared with that one.

\section{Factors affecting plant susceptibility to air pollutants}

Differences among plants species in ozone sensitivity have been attributed to the following factors:

- Stomatal conductance

- Intercellular leaf volume

- Soluable sugar or ascorbate contents

(Sandermann, 1996)

It is very important to note that; plants species which are sensitive to one air pollutant can also be susceptible to other pollutants (Treshow and Lacasse, 1976). After stomatal uptake, the intercellular tissue concentration of ozone rapidly declines. Although this indicates detoxification, the ozone decomposition products or second messenger molecules can affect photosynthesis or gene expression to an extend determined by the external ozone concentration. For instance, in tobacco the induced transcripts (ozone-induced gene-expressions) are; basic B-1, 3-glucanase (intermediate response; 3-8 hours), basic chitinase (late response; $8-48$ hours after onset ozone exposure, usually with beginning lesion formation), acidic chitinase (late response), pathogenesis-related $1 \mathrm{~b}$ (late response), catalase 2 fast response) and lipidperoxide- 
dependent GSH peroxidase (intermediate response). At this stage, most of the ozone is decomposed in apoplast by the relatively harmless oxidation of cell wall components. Well documented ozone effects on chloroplast functions and nuclear gene expression occur by unknown mechanisms, possibly involving an ozone receptor, an oxidant burst and signal chains. The effects are often linked to a second stressor and can eventually lead to visible effects (Sandermann, 1996; Mandercheid, et al., 1991). It is not yet clear whether an oxidative burst occurs and wheather visible lesions are caused by ozone through a program of local cell death (apoptosis) similar to that postulated for the hypersensitive response induced in compatible plant-pathogene interactions. Membrane lysis and chlorotic or necrotic symptoms usually occur as rather late ozone effects. Often a second stressor such as frost, drought or pathogene seems to participate. Ozone phytotoxicity involves visual symptoms and growth effects as well as the problem of leaf internal ozone dose, effects on stomatal regulations, photosynthetic functions and assimilate allocation. Inhibition of primary plant metabolism by ozone leads to a general reduction of growth and competitive fitness of the plant. Ozone effects are usually twofold; an initial phase of stress reactions and lowered photosynthesis may or may not be followed by a second phase of visible symptom development (chlorotic and necrotic lesions). Symptom development may be fast in herbaceous plants or may be delayed by many months in conifers (Sandermann, 1996; Schmieden and Wild, 1994).

\section{Results}

Nine rounds of fumigation were carried out 6 years ago. During this period, test plants were subjected to ozone gas with 3 different concentrations $(7.5,16,26 \mathrm{pphm})$. The open chamber method which was used for these experiments facilitated the classification of the test plants susceptibilities. Bel-W3 showed severe injuries when the ozone concentration was $16 \mathrm{pphm}$. The commencement of leaves wilting conditions of Dynes, Weather Fleck, and ZZ100 appeared when the concentration of ozone was $16 \mathrm{pphm}$. The severity of wilting conditions on the test plants leaves and details of other major symptoms are available in Tables 2, 3, 4 and 5. Bel-B did not show any symptoms during fumigation.

\section{Discussion and Conclusion}

Experimental fumigation with ozone was carried out by an open chamber system. Installation of a powerful ozone generator is suitable for this purpose. One outcome of the present work was the refinement of exposure techniques for short-term studies of ozone impact on plants. The following requirements were identified; Injury can be assessed reliably on plants with leaves that are more than $70 \%$ of their final area, so that stomatal are functional. Air flow rates over the plants in the fumigation cabinet should be equivalent to two or three air changes per minute or wind speeds should exceed $1 \mathrm{~m} . \mathrm{s}^{-1}$ in order to maintain high and consistent boundary layer conductances. Air flow among plants should not be impeded by crowding, and air flow within plants should be considered when assessing the patterns of development of injury. Plants should be wellwatered before each experiment to optimise stomatal opening. The ozone concentration in the cabinet should be adjusted with a set of plants in the cabinet that are similar in number and size to the experimental set. Pots containing the experimental plants should be enclosed in polyethylene bags in order to minimize ozone absorption by the soil in the pots. The provision of a suitable quantity of ozone, and the maintenance stable cabinet conditions by allowing an exchange of air between the cabinet and outside environment enabled experiments to be conducted that demonstrated reasonably consistent responses to variations in ozone concentration. No injurious effects were observed when Nicotiana tabacum cv. Bel-W3 plants were exposed to $7.5 \mathrm{pphm}$ ozone, about $20 \%$ of leaf area showing injury at $16 \mathrm{pphm}$, and also about $35 \%$ injury at $26 \mathrm{pphm}$. Three concentrations represent the minimum number to discern a pattern of response, and the almost linear relationship between leaf area injured and concentration suggests that the threshold for injury may be close to the treatment concentration of $7.5 \mathrm{pphm}$. This concentration is consistent with the minimum one-hour average concentrations of between 7.6 and 8.8 $\mathrm{pphm}$, recorded in the field in association with the occurrence of injury to the same variety of tobacco. 
Table 2: Results of six rounds of fumigation on Nicotiana tabacum cv. Bel-W3 leaves

\begin{tabular}{|ccccccccccc|}
\hline $\begin{array}{c}\text { Fumigation } \\
\text { number }\end{array}$ & $\mathrm{O} 3(\mathrm{pphm})$ & \multicolumn{9}{c|}{ Leaf number } \\
\cline { 2 - 11 }$y$ & & $\mathrm{n}-1$ & $\mathrm{n}-2$ & $\mathrm{n}-3$ & $\mathrm{n}-4$ & $\mathrm{n}-5$ & $\mathrm{n}-6$ & $\mathrm{n}-7$ & $\mathrm{n}-8$ \\
\hline 4 & 16 & 0 & 0 & 0 & $30 \%$ & $10 \%$ & $20 \%$ & 0 & 0 \\
\hline 5 & 16 & 0 & 0 & 0 & $7.5 \%$ & $8 \%$ & $20 \%$ & 0 & 0 \\
\hline 6 & 16 & 0 & 0 & 0 & $40 \%$ & $37 \%$ & $5 \%$ & 0 & 0 \\
\hline Mean & 16 & 0 & 0 & 0 & $25.8 \%$ & $18.3 \%$ & $5 \%$ & 0 & 0 \\
\hline 7 & 26 & 0 & 0 & $30 \%$ & 0 & $40 \%$ & 0 & $60 \%$ & 0 \\
\hline 8 & 26 & 0 & 0 & 0 & $35 \%$ & 0 & 0 & 0 & 0 \\
\hline 9 & 26 & 0 & 0 & 0 & 0 & $25 \%$ & $20 \%$ & $50 \%$ & $35 \%$ \\
\hline Mean & 26 & 0 & 0 & $10 \%$ & $11.6 \%$ & $21.6 \%$ & $6.6 \%$ & $36.6 \%$ & $11.6 \%$ \\
\hline
\end{tabular}

Table 3: Results of six rounds of fumigation on Nicotiana tabacum cv. Dynes leaves

\begin{tabular}{|c|c|c|c|c|c|c|c|c|c|}
\hline \multirow{2}{*}{$\begin{array}{c}\text { Fumigation } \\
\text { number }\end{array}$} & \multirow[t]{2}{*}{$\mathrm{O} 3(\mathrm{pphm})$} & \multicolumn{7}{|c|}{ Leaf number } & \multirow[b]{2}{*}{$n-8$} \\
\hline & & $n-1$ & $n-2$ & $n-3$ & $\mathrm{n}-4$ & $n-5$ & $n-6$ & $n-7$ & \\
\hline 4 & 16 & $\mathrm{~S}$ & $\mathrm{~S}$ & Ws & Ws & Ws & Ws & $\mathrm{W}$ & $\mathrm{W}$ \\
\hline 5 & 16 & 0 & 0 & Yf & Ws & $\mathrm{W}$ & Ws & $\mathrm{W}$ & $\mathrm{W}$ \\
\hline 6 & 16 & 0 & 0 & 0 & 0 & $30 \%$ & 0 & 0 & 0 \\
\hline 7 & 26 & 0 & $S$ & Ws & Yf & Ws & Ws & $\mathrm{W}$ & $\mathrm{W}$ \\
\hline 8 & 26 & 0 & 0 & Yf & Ws & Ws & Ws & Ws & W \\
\hline 9 & 26 & $S$ & $S$ & $\mathrm{~W}$ & $35 \%$ & $\mathrm{~W}$ & Ws & Ws & $\mathrm{W}$ \\
\hline
\end{tabular}

Table 4: Results of four rounds of fumigation on Nicotiana tabacum cv. Weather Fleck leaves

\begin{tabular}{|cccccccccc|}
\hline $\begin{array}{c}\text { Fumigation } \\
\text { number }\end{array}$ & O3 $(\mathrm{pphm})$ & \multicolumn{1}{c|}{ Leaf number } \\
\cline { 2 - 11 }$y-4$ & $\mathrm{n}-1$ & $\mathrm{n}-2$ & $\mathrm{n}-3$ & $\mathrm{n}-4$ & $\mathrm{n}-5$ & $\mathrm{n}-6$ & $\mathrm{n}-7$ & $\mathrm{n}-8$ \\
\hline 6 & 16 & 0 & 0 & $\mathrm{~W}$ & $\mathrm{~W}$ & $\mathrm{~W}$ & $\mathrm{~W}$ & 0 & 0 \\
\hline 7 & 26 & 0 & 0 & 0 & 0 & 0 & 0 & 0 & 0 \\
\hline 8 & 26 & 0 & 0 & 0 & 0 & 0 & 0 & 0 & 0 \\
\hline 9 & 26 & 0 & $\mathrm{~W}$ & $\mathrm{~W}$ & $\mathrm{~W}$ & $\mathrm{~W}$ & $\mathrm{~W}$ & $\mathrm{~W}$ & $\mathrm{~W}$ \\
\hline
\end{tabular}

Table 5: Results of four rounds of fumigation on Nicotiana tabacum cv. ZZ100 leaves

\begin{tabular}{|c|c|c|c|c|c|c|c|c|c|}
\hline \multirow{2}{*}{$\begin{array}{c}\text { Fumigation } \\
\text { number }\end{array}$} & \multirow[t]{2}{*}{ O3 (pphm) } & \multicolumn{7}{|c|}{ Leaf number } & \multirow[b]{2}{*}{$\mathrm{n}-8$} \\
\hline & & $\mathrm{n}-1$ & $n-2$ & $n-3$ & $n-4$ & $n-5$ & $n-6$ & $n-7$ & \\
\hline 6 & 16 & 0 & 0 & $\mathrm{~W}$ & 0 & 0 & 0 & 0 & 0 \\
\hline 7 & 26 & 0 & 0 & 0 & 0 & 0 & 0 & 0 & 0 \\
\hline 8 & 26 & 0 & 0 & 0 & 0 & 0 & 0 & 0 & 0 \\
\hline 9 & 26 & 0 & $\mathrm{~W}$ & $\mathrm{~W}$ & $\mathrm{~W}$ & $\mathrm{~W}$ & 0 & 0 & 0 \\
\hline
\end{tabular}

\section{List of abbreviations;}

\section{Con = concentration}

Temp. $=$ temperature

PAR = photosynthetically Active Radiation

Av.w =average wet bulb

Av. =average

${ }^{\circ} \mathrm{C}=$ centigrade

$\mu \quad=$ micro

mol $=$ mole $\mathrm{m} \quad=$ metre

$\mathrm{s} \quad=$ second

$\mathrm{S} \quad=$ sticky surface of the leaves

$\mathrm{W} \quad=$ wilting conditions of the leaves

Ws = wilting +silvery colours of the leaves

Yf = rare yellow flecks of the leaves

$0 \quad=$ leaves did not show any kinds of injury

pphm $=$ part per hundred million 


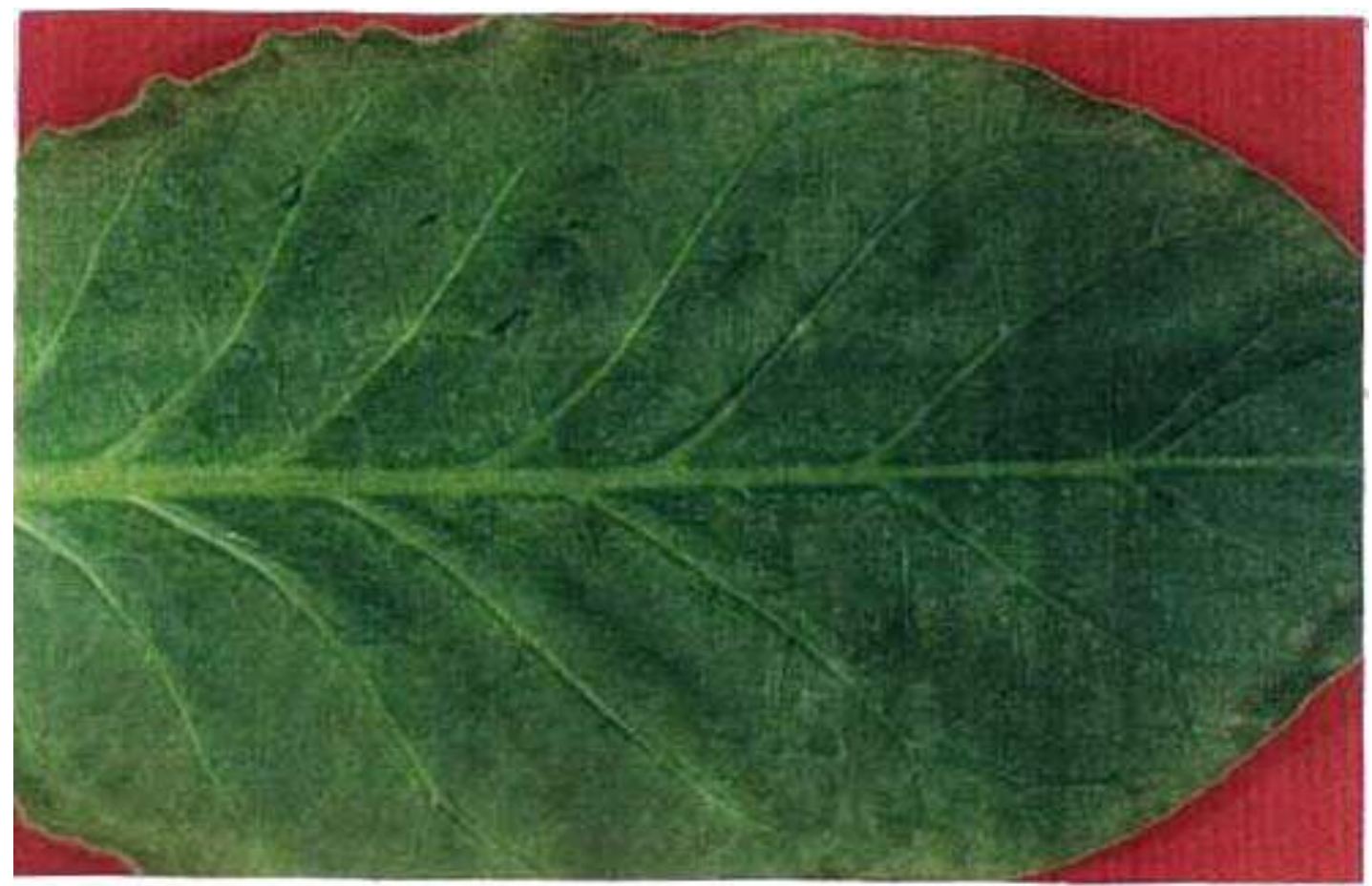

Figure 2: Leaf of Nicotina tabacum cv. Bel-W3 exposed to 26 pphm for 7 hours during $8^{\text {th. }}$ fumigation. Ozone injury is visible in form of scattered yellow flecks on the surface of the leaf

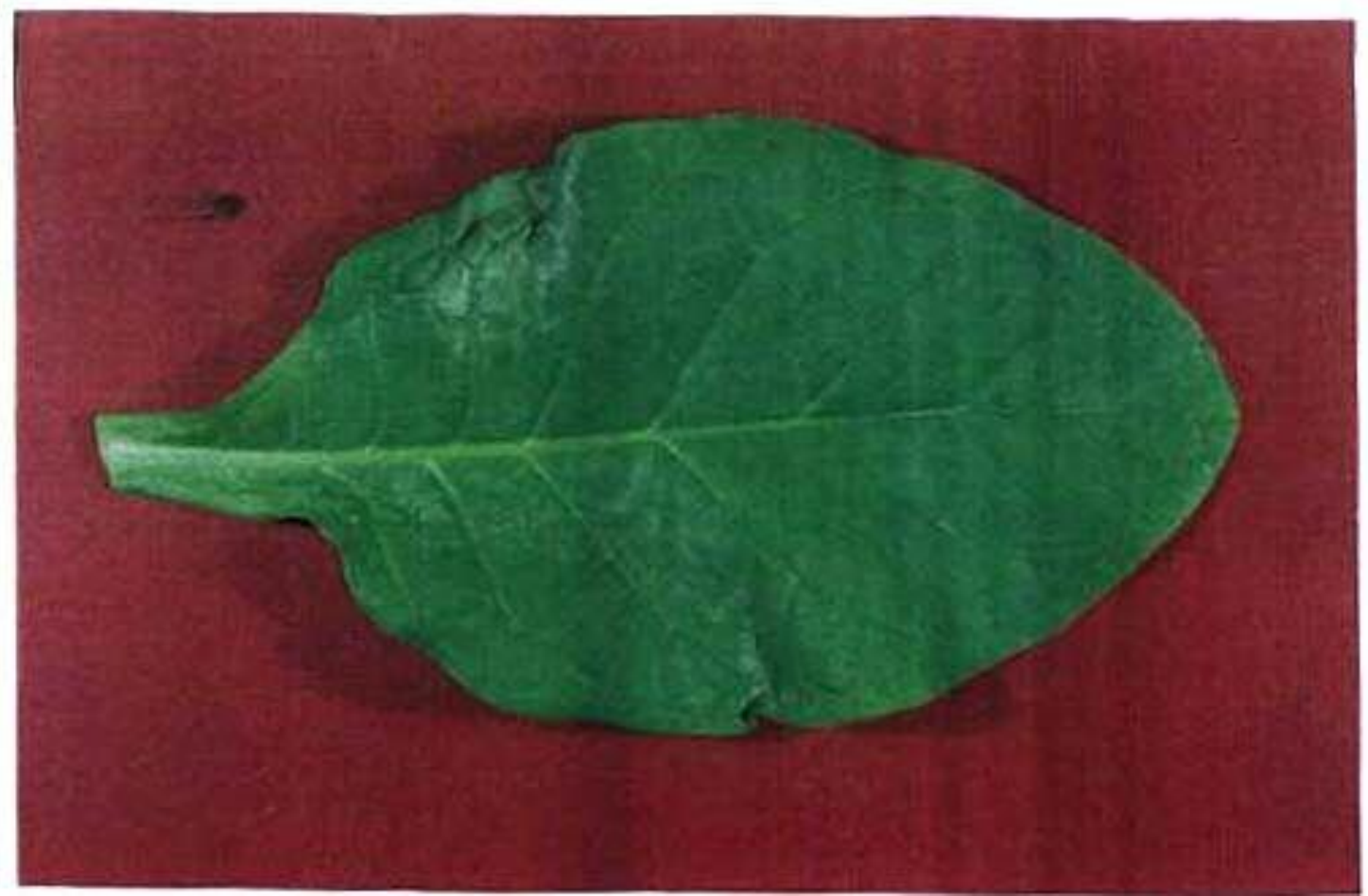

Figure 3: Leaf of Nicotiana tabacum cv. Dynes exposed to $26 \mathrm{pphm}$ for 7 hours during $9^{\text {th. }}$ fumigation. Light grey spots which are visible at the top of the leaf and at the lower part are the result of ozone effect 
Ozone injury varied in its extent among plants in any fumigation, and among leaves within a single plant. Some plants of each variety in each treatment were free from visible injury, whilst in others almost all mature leaves were injured. There was not a clear distinction between the amount of injury that appeared in leaves of different age. In several plants the extent of injury in the oldest leaves was least, with the youngest leaves being injured more, and the middle-aged leaves injured most. However, in some plants the extent of injury varied greatly among adjacent leaves, and this variation did not appear to be associated with any plant or experimental condition.

Air temperature varied among the experimental series, due to the fact that the chamber doors were kept open to admit outside air. The 7.6 and $26 \mathrm{pphm}$ treatments were imposed at temperatures between $24^{\circ} \mathrm{C}$ and $35^{\circ} \mathrm{C}$, whilst the $16 \mathrm{pphm}$ treatment was imposed at $16^{\circ} \mathrm{C}$ to $29^{\circ} \mathrm{C}$. It is not possible to determine whether the temperature had an effect on the response of the plants to ozone, but the approximately linear relationship between ozone concentration and injury suggests that temperature was not a major effect.

Variation in symptom expression among the varieties of tobacco was distinct. Tobacco cv. Bel-W3 was clearly the most sensitive to ozone, followed by tobacco cv. Dynes which showed some typical bleaching injury and wilting. This variety also exuded a sticky resinous material when injured, and some leaves developed a general silvery colour. Tobacco cv.Weather Fleck, which had been suspected of being very susceptible to ozone injury, did not show the typical bleaching symptom under experimental conditions. The cvs. ZZ100 and Bel-B did not exhibit any injury symptoms during these experiments. Tobacco cv. Bel-B is recognised as being resistant to ozone injury, and the locally grown cv. ZZ100 can also be placed in this category.

It is concluded that the prominent wilting of tobacco cv.Dynes and Weather Fleck in response to exposure to $16 \mathrm{pphm}$ ozone may contribute to ozone resistance, but it does not explain the appearance of weather fleck in an environment expected to have low ozone concentrations. Meanwhile, it was not possible to measure stomatal conductance during the present studies, but it could be expected that conductance decreased substantially during the wilting process.

After experiments, the results exhibit that tobacco cv. Bel-W3 is supersensitive to ozone, Dynes has the second rank, Weather Fleck has the third rank from susceptibility point of view, Bel-B and ZZ100 are tolerant. Classification of these five varieties of tobacco in comparison to each other was for the first time. Awareness of this scientific fact will assist field biomonitoring, significantly.

\section{Acknowledgements}

The author is indebted to Drs. D. Doley, R. Riese, V. A. Sisson, A. E. G. Tonneijck, D. Neale for their scientific supports and Mr. D. Wainwright, P. Kingston and G. Andrews for their skillful technical assistances.

\section{References}

Lee, E. H., Chlorophyll fluorescence as an indicator to detect differential tolerance of snapbean cultivars in response to O3 stress. Taiwania, 36: 220-234, 1991

Mandercheid, R., Jager, H. J., Schoeneberger, Dose-response relationship of ozone effects on foliar levels of antioxidants, soluable polyamines and peroxydase activity of Pinus taeda (L.). Assessment of the usefulness as early ozone indicators. Vereinigung fur angewandte botanik, 65:373-386, 1991

Mooi, J., Practical problems of physical environment of open top chambers, measurement techniques, Microclimate and plant growth in open top chambers. Air pollution research report, Commission of European Communities, 5: 30-43, 1986

Mooi, J. and H. H. W. Jolink, Computer controlled plant growth cabinets for fumigation experiments/ Environmental research with plants in closed chambers. In proceedings of an international symposium, Commission of European Communities, 26: 43-51, 1989

Posthumus, A. C., Experimentelle untersuchungen der wirkung von ozon und peroxyacetylnitrat (PAN) auf pflanzen. VDI-Berichte, 270:153-161, 1977

Sandermann, H. (Jr.), Ozone and plant health. Phytopathology, 34 347-366, 1996

Schmieden, U. and A. Wild, Changes in levels of atocopherol and ascorbate in spruce needles to $\mathrm{Mg}^{2^{+}}$deficiency and ozone, Zeitshrift fur 
M. Azadi

Naturforschung, Section G. Biosciences, 49: 171180, 1994

Sun E. J., Ozone injury to leafy sweet potato and spinach in northern Taiwan. Botanical bulletin of academia sinica Taipei,35 165-170, 1994

Tingey, D. T., R. A. Reinert, J. A. Dunning and W. W. Heck, Foliar injury responses of eleven plant species to ozone/sulfur dioxide mixtures. Atmospheric environment, 7: 201-208, 1972

Tonneijck A. E. G., Effects of various ozone exposures on the susceptibility of bean leaves (Phaseolus vulgaris L.) to Botrytis cinerea. Environmental pollution, 85:59 65, 1994
Tonneijck A. E. G. and G. Leone, Changes in susceptibility of bean leaves (Phaseolus vulgaris to Sclerotinia sclerotiorum and Botrytis cinerea by preinoculative ozone exposures. Plant Pathology, 99 313-322, 1993

Treshow M. and N. L. Lacasse, Diagnosing vegetation injury caused by air pollution. Applied science associates INC., U.S.A., (developed for Environmental Protection Agency of the U.S.A.), 1997 